\title{
Synthesis and study of structural properties of Sn doped ZnO nanoparticles
}

\author{
M. Arshad JAVid ${ }^{1 *}$, M. RAFi ${ }^{1}$, IhSAn Ali $^{2}$, FAYyaz Hussain $^{3}$, M. Imran $^{3}$, Ali Nasir $^{4}$ \\ ${ }^{1}$ Department of Basic Sciences (Physics), University of Engineering \& Technology, Taxila, Pakistan \\ ${ }^{2}$ Government Municipal Postgraduate College, Toba Tek Singh, Pakistan \\ ${ }^{3}$ Department of Physics, Bahudin Zikria University, Multan, Pakistan \\ ${ }^{4}$ Department of Mechanical Engineering, UET, Taxila, Pakistan
}

\begin{abstract}
Pure and $\mathrm{Sn}$-doped $\mathrm{ZnO}$ nanostructures were synthesized by simple chemical solution method. In this method we used zinc nitrate and $\mathrm{NaOH}$ as precursors. Sn doping content in $\mathrm{ZnO}$ was taken with the ratio 0, 5, 10, 15 and 20 percent by weight. Physical properties of Sn-doped $\mathrm{ZnO}$ powder were studied by XRD analysis which revealed that Sn doping had a significant effect on crystalline quality, grain size, intensity, dislocation density and strain. The calculated average grain size of pure $\mathrm{ZnO}$ was $21 \mathrm{~nm}$. The best crystalline structure was found for $0 \mathrm{wt} . \%, 5 \mathrm{wt} . \%$ and $10 \mathrm{wt}$.\% Sn doping as observed by FESEM and XRD. However, higher Sn-doping ( $>10 \mathrm{wt} . \%$ ) degraded the crystallinity and the grain size of $27.67 \mathrm{~nm}$ to $17.76 \mathrm{~nm}$. The structures observed in FESEM images of the samples surfaces were irregular and non-homogeneous. EDX depicted no extra peak of impurity and confirmed good quality of the samples.
\end{abstract}

Keywords: nanoparticles; chemical solution method; physical properties; XRD analysis

(C) Wroclaw University of Technology.

\section{Introduction}

Zinc oxide is a type of semiconductor material having band gap of $3.37 \mathrm{eV}$ and high binding energy of $60 \mathrm{MeV}$. $\mathrm{ZnO}$ materials are used in solar cells, UV detectors, gas sensors and photo catalysts, because of good optical, optoelectronic and piezoelectric properties [1]. $\mathrm{ZnO}$ properties can be improved using different techniques [2, 3]. $\mathrm{ZnO}$ is an excellent nanoscale metal oxide. $\mathrm{ZnO}$ is an n-type II - VI semiconductor having normally a hexagonal or wurtzite structure. $\mathrm{ZnO}$ microstructure has found novel applications in gas sensors, solar cells, varistors and photocatalyst with high chemical activity [4-7]. $\mathrm{ZnO}$ based improvements have been made on nanomaterials in basic sciences and advanced material engineering [8,9]. $\mathrm{Sn}$ is an active n-type dopant in $\mathrm{ZnO}$. The radius of $\mathrm{Sn}^{+4}$ $(0.071 \mathrm{~nm})$ is almost equivalent to $\mathrm{Zn}^{+2}(0.074 \mathrm{~nm})$ which is favorable in substituting $\mathrm{Zn}$ ions in $\mathrm{ZnO}$

*E-mail: arshad.javid@uettaxila.edu.pk lattice in order to adjust visible emission of $\mathrm{ZnO}$ materials by Sn-doping [10-12]. Sn doped ZnO was successfully synthesized and its physical and chemical properties were studied [13]. The improvement of zinc oxide properties has been proposed by the refinement of its nanostructure and optimizing its morphology $[14,15]$.

Different synthesis techniques of $\mathrm{ZnO}$ particles have been reported [16-20]. In this work, we synthesized the Sn doped $\mathrm{ZnO}$ nanoparticles using chemical solution method. XRD, FESEM and EDX analyses have been carried out.

\section{Experimental}

\subsection{Synthesis of $\mathrm{Sn}$ doped $\mathrm{ZnO}$ nanopar- ticles}

Sn doped $\mathrm{ZnO}$ nanoparticles have been synthesized using a simple chemical solution method. The stock solutions of starting materials $50 \mathrm{mM}$ zinc nitrate $\mathrm{Zn}\left(\mathrm{NO}_{3}\right)_{2} \cdot 2 \mathrm{H}_{2} \mathrm{O}, 50 \mathrm{mM}$ stannic chloride $\mathrm{SnCl}_{4} \cdot 5 \mathrm{H}_{2} \mathrm{O}$ and $100 \mathrm{mM}$ sodium hydrate 
$\mathrm{NaOH}$ were prepared using deionized water as a solvent for each sample. The solution of $\mathrm{NaOH}$ was dropped into the solution of $\mathrm{Zn}\left(\mathrm{NO}_{3}\right)_{2} \cdot 2 \mathrm{H}_{2} \mathrm{O}$ under continuous magnetic stirring till the formation of white precipitates of $\mathrm{Zn}(\mathrm{OH})_{2}$. The precipitates were filtered off and washed with distilled water for five times. The precipitates of $\mathrm{Zn}(\mathrm{OH})_{2}$ were first dried in air at room temperature and then heated at $250{ }^{\circ} \mathrm{C}$ for 24 hours to attain fine crystallinity. For the preparation of $5 \mathrm{wt} . \%, 10 \mathrm{wt} . \%, 15 \mathrm{wt} . \%$ and $20 \mathrm{wt} . \% \mathrm{Sn}$ doped zinc oxide, the stock solutions of $50 \mathrm{mM} \mathrm{Zn}\left(\mathrm{NO}_{3}\right)_{2} \cdot 2 \mathrm{H}_{2} \mathrm{O}$ and $50 \mathrm{mM} \mathrm{SnCl} 4 \cdot 5 \mathrm{H}_{2} \mathrm{O}$ were mixed accordingly to each composition and the same procedure as used for the preparation of $\mathrm{ZnO}$ was adopted for each case.

The synthesized samples were characterized using a Rigaku XRD instrument with monochromatic $\mathrm{CuK} \alpha$ radiation source having wavelength of $1.5418 \AA$. The morphology studies and compositional analysis of nanoparticles were carried out by FESEM integrated with EDX (TIMA3 LM TESCAN). The samples were coated with carbon using low voltage sputtering and then analyzed under SEM operating at a voltage of $20 \mathrm{kV}$.

\section{Results and discussion}

\subsection{Structural parameters}

Fig. 1a shows the XRD patterns of $\mathrm{ZnO}$ with $0 \%$ Sn concentration. The X-ray diffraction patterns of samples $\mathrm{a}, \mathrm{b}$ and $\mathrm{c}$ are consistent with the reference codes 01-005-0664 and 01-075-0576. The peak with (h k l) value $\left(\begin{array}{lll}1 & 0 & 1\end{array}\right)$ positioned at $36.36^{\circ}$ has maximum intensity. The (llll $\left.\begin{array}{lll}1 & 1\end{array}\right)$ major plane along with some other minor planes indicate the polycrystalline nature of the prepared material having hexagonal geometry [21, 22].

When the Sn doping of $\mathrm{ZnO}$ material increased above $10 \mathrm{wt} . \%$, the intensity of the major peak has increased showing the improvement in the crystallinity [23]. Beyond 10 wt.\% Sn doping, the decrease in intensity of the major peak corresponding to $\left(\begin{array}{lll}0 & 1 & 5\end{array}\right)$ plane has been observed what indicates poor crystallinity. Sn doping has improved the crystallinity up to the concentration level of $10 \mathrm{wt} . \%$ but $\mathrm{ZnO}$ crystal structure showed poor crystallinity above the Sn concentration level of $10 \mathrm{wt} . \%$.



Fig. 1. X-ray diffraction peaks of 0 wt. $\%, 5$ wt. $\%, 10$ wt.\%, 15 wt.\% and $20 \mathrm{wt} . \%$ Sn doped zinc oxide.

The grain sizes of the prepared samples were calculated using Debye-Scherrer's formula [24]:

$$
d=\frac{K \lambda}{\beta \cos \theta}
$$

where $\mathrm{d}$ is the grain size, $\mathrm{k}$ is a constant taken to be 0.89 for the hexagonal structure, $\lambda$ is the wavelength of X-ray used (1.5418 $\AA$ ), $\beta$ is full width at half maximum and $\theta$ is the Bragg's angle. Equation 1 is multiplied by a factor $\pi / 180$ to change the value of $\mathrm{W}$ from degree to radian:

$$
d=\frac{K \lambda}{\beta \cos \theta} \cdot \frac{\pi}{180}
$$

Table 1. Variation of grain size with the increase of $\mathrm{Sn}$ content in $\mathrm{Zn}_{1-\mathrm{x}} \mathrm{Sn}_{\mathrm{x}} \mathrm{O}$ ( $\mathrm{x}=0.00$ to 0.20) [33]

\begin{tabular}{ccccc}
\hline $\mathrm{x}$ & $2 \theta$ & \multicolumn{1}{c}{ FWHM } & Intensity [a.u.] Grain size [nm] \\
\hline \hline 0.00 & 36.2 & 0.006671 & 679.96 & 21.3270 \\
0.05 & 36.2 & 0.005137 & 814.26 & 27.663 \\
0.10 & 36.2 & 0.00521 & 377.49 & 25.272 \\
0.15 & 36.2 & 0.00676 & 122.60 & 21.028 \\
0.20 & 36.2 & 0.0080 & 71.8320 & 17.763 \\
\hline
\end{tabular}

The calculated average grain size of pure $\mathrm{ZnO}$ is $21 \mathrm{~nm}$ and it decreases up to $17 \mathrm{~nm}$ for $20 \mathrm{wt}$.\% Sndoped sample. The variation in grain size with the 
increase in Sn concentration is shown in Fig. 2 and Table 1. The grain size decreases with Sn content which is likely due to the substitution of Sn metal into zinc oxide lattice $[25,26]$.

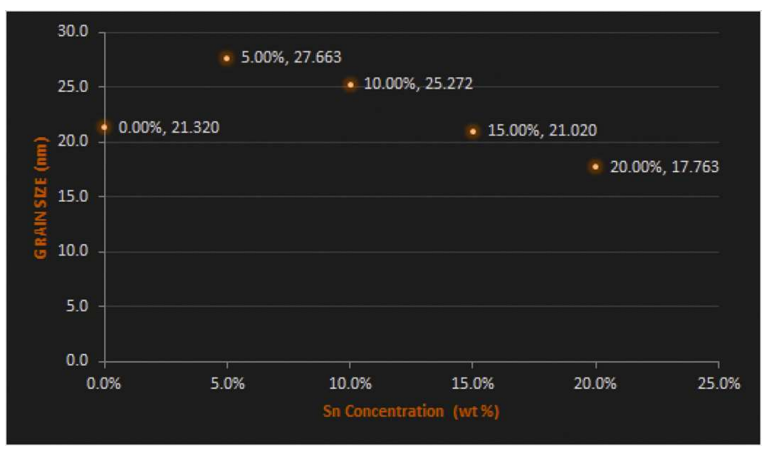

Fig. 2. Grain size versus $\mathrm{Sn}$ content of $\mathrm{ZnO}$ nanoparticles.

The strain produced in the samples due to $\mathrm{Sn}$ doping has been calculated using the relation [27]:

$$
€=\frac{\beta \cos \theta}{4}
$$

where $€$ is strain and $\theta$ is the Bragg's angle in degrees.

Dislocation density was calculated by [28]:

$$
\delta=\frac{1}{d^{2}}
$$

The dislocation density $(\delta)$, defined as the length of dislocations lines per unit volume has been estimated using equation 4.

Table 2. Calculation of strain, and dislocation density with an increase of Sn content in $\mathrm{Zn}_{1-\mathrm{x}} \mathrm{Sn}_{\mathrm{x}} \mathrm{O}$ $(\mathrm{x}=0.00$ to 0.20$)$.

\begin{tabular}{cccc}
\hline $\mathrm{x}$ & $\begin{array}{c}\text { Strain } \\
(€)\end{array}$ & $\begin{array}{c}\text { Grain } \\
\text { size }[\mathrm{nm}]\end{array}$ & $\begin{array}{c}\text { Dislocation density } \\
(\delta)\left[\text { lines } / \mathrm{m}^{2}\right]\end{array}$ \\
\hline \hline 0.00 & 0.001584 & 21.3270 & 0.00212 \\
0.05 & 0.00122 & 27.663 & 0.00130 \\
0.10 & 0.00123 & 25.272 & 0.00161 \\
0.15 & 0.0016 & 21.028 & 0.00226 \\
0.20 & 0.0019 & 17.763 & 0.00317 \\
\hline
\end{tabular}

Calculated values of strain and dislocation density are presented in Table 2.
The effect of strain in $\mathrm{ZnO}$ nanoparticles due to Sn dopant is demonstrated by the grain size $(d)$, strain $(€)$, and dislocation density $(\delta)$ given in Table 2. For the samples with Sn-doping concentration of $5 \mathrm{wt} \%$, the grains tend to increase in size because of the small strain in the sample that influences the normal growth of $\mathrm{ZnO}$. However, when Sn-doping concentration is $10 \mathrm{wt} . \%$, the grain size slightly decreases because of higher strain. This shows again that the best crystalline structure is achieved only up to $10 \mathrm{wt}$.\% Sn doping as previously followed from XRD analysis. At higher doping up to $10 \mathrm{wt} \%$, the grain size decreases again as a result of greater stress leading to poor crystallinity. It should be mentioned that the strain value $(€)$ depends on both $\beta$ and $\cos \theta$ as shown in equation 3 . Dislocation density $(\delta)$ may also be considered as a measure of crystallinity. Among the different doping concentrations 5 wt.\% and $10 \mathrm{wt} . \%$ doping give the smallest $(\delta)$ which shows the best crystalline structure compared to higher or lower doped ones [29].

The microstructure and morphology of nanoparticles were analyzed using FESEM. Fig. 2 shows the micrographs of the samples of $\mathrm{Sn}$ doped $\mathrm{ZnO}$ nanoparticles. The images show clearly the morphological changes due to the different doping levels of $\mathrm{Sn}$ in $\mathrm{ZnO}$. The $\mathrm{Sn}$ doped $\mathrm{ZnO}$ nanoparticles are inhomogeneous in nature. Interestingly, when we increase the doping rate, the morphological changes of the microstructure show the mechanism of nucleation and/or wrinkles growth [30]. These variations are produced by $\mathrm{Sn}$ atoms which promote the growth of network-winkles destressing the microstructure and reducing energy of the system. Similar result was presented by Bahsi et al. [31] in the study of the effect of $\mathrm{Mn}$ and $\mathrm{Cu}$ doping on microstructure of $\mathrm{ZnO}$. Furthermore, the surface micrographs showed that the doping of Sn plays an important role in changing and improving the structure of the $\mathrm{ZnO}$ nanoparticles. The ratio of $\mathrm{Sn}$ is the main factor that controls the morphology and structure of the final product. This may be due to the defects created by Sn doping. The size of these crystalline structures varies in the range 

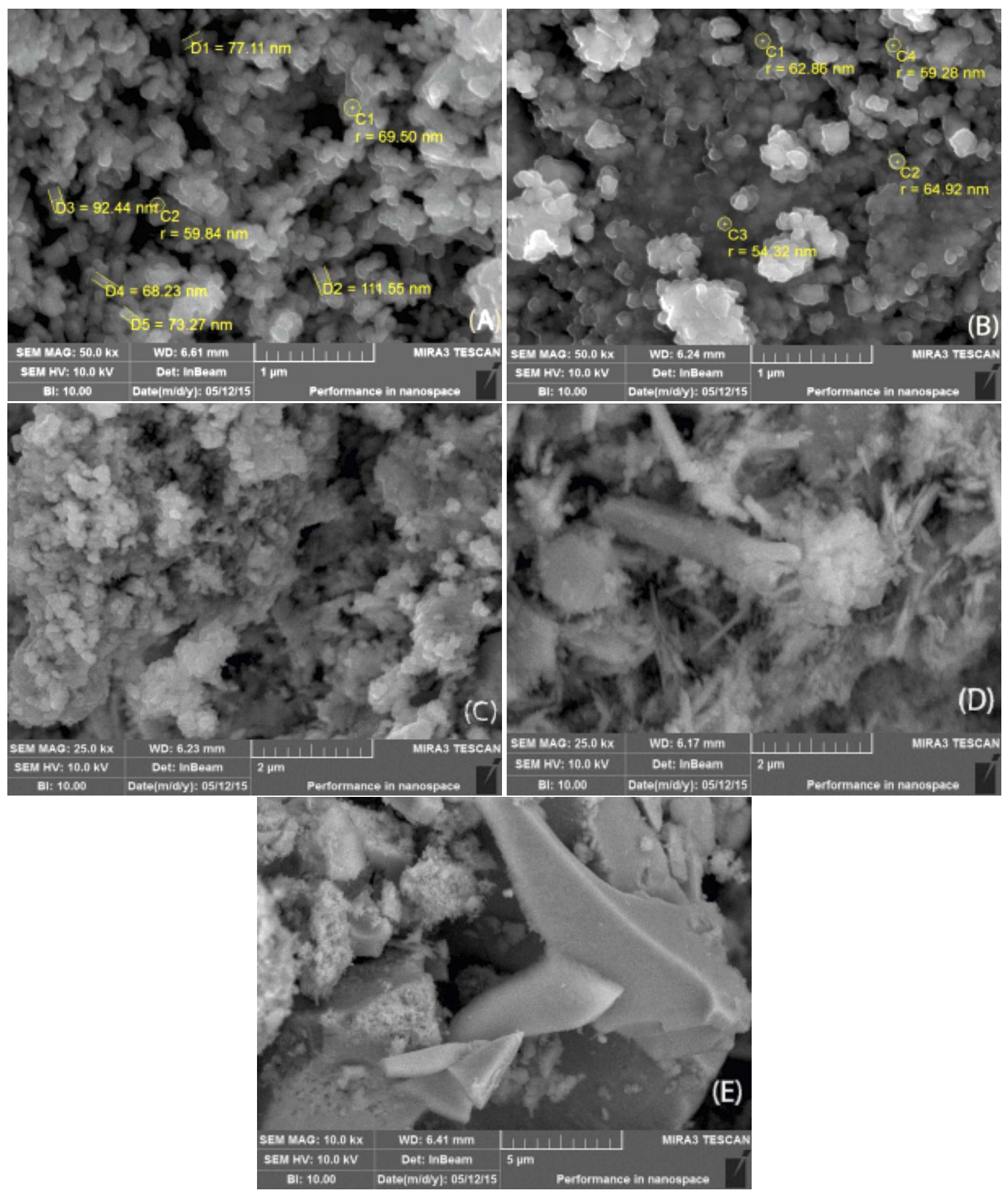

Fig. 3. FESEM micrographs for different concentrations of Sn doped $\mathrm{ZnO}$ nanoparticles (A) 0 wt.\%; (B) 5 wt.\%; (C) 10 wt.\%; (D) 15 wt.\%; (E) 20 wt.\%.

of $\sim 54 \mathrm{~nm}$ to $111 \mathrm{~nm}$ in Fig. 3A and Fig. 3B. crystal results from the driving force of the dopant When the concentration of $\mathrm{Sn}$ dopant increased on $\mathrm{ZnO}$ lattice, hence, Sn-doped $\mathrm{ZnO}$ nanostrucfrom $5 \mathrm{wt} \%$ to $10 \mathrm{wt} \%$, the Sn-doped $\mathrm{ZnO}$ tures have a granular shape as shown in Fig. 3A to nanoparticles showed noticeable variations in the Fig. 3C. Furthermore, ZnO nanoparticles at higher surface morphology [32]. Anisotropic growth of Sn concentrations (above $10 \mathrm{wt} \%$ ), (Fig. 3D and 


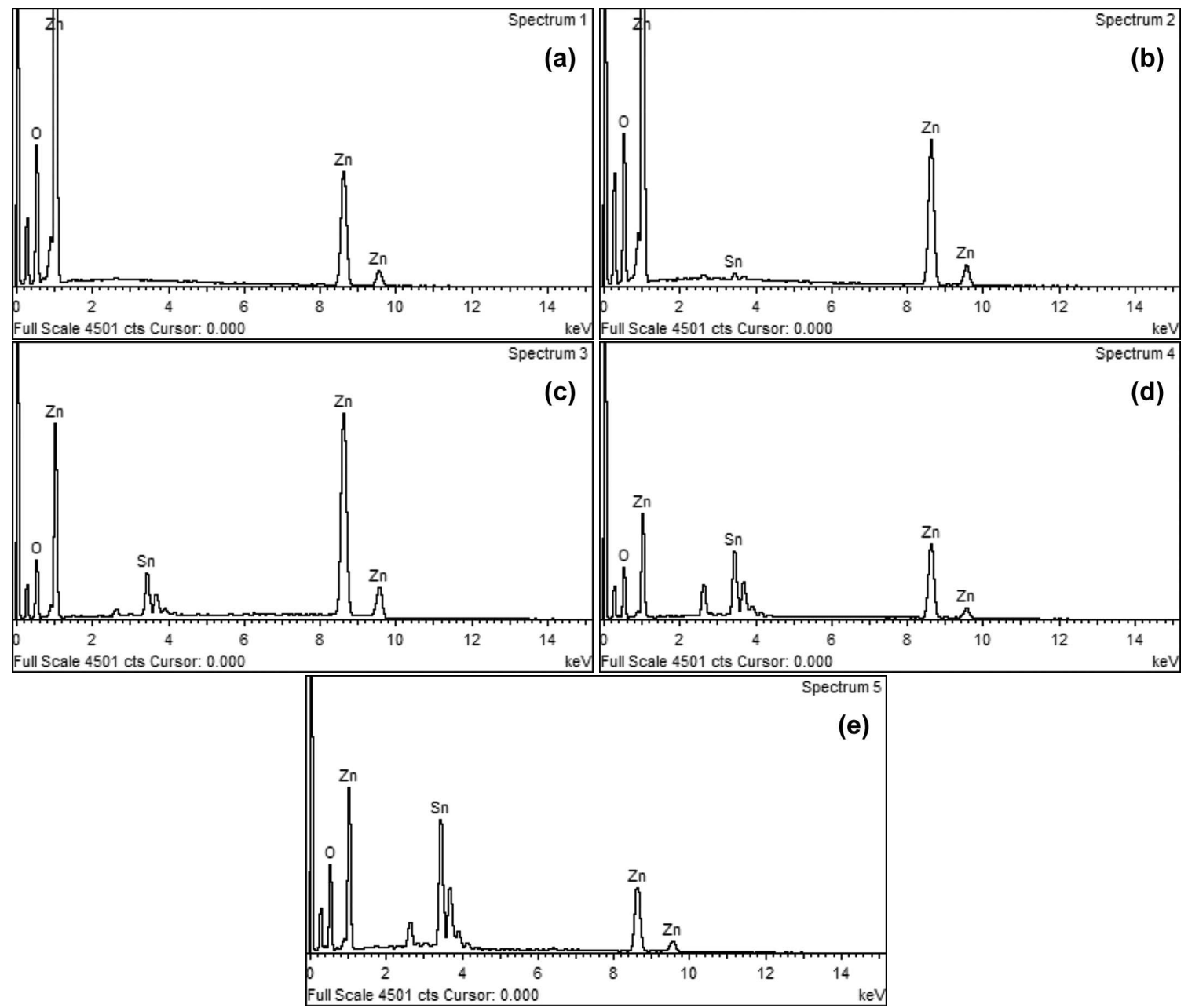

Fig. 4. EDX spectra of $\mathrm{ZnO}$ nanoparticles doped by different concentrations of $\mathrm{Sn}$ (a) 0 wt.\%; (b) 5 wt.\%; (c) 10 wt.\%; (d) 15 wt.\%; (e) 20 wt.\%.

Fig. 3E) tend to agglomerate and show irregular flake structure [32].

EDX analysis was carried out to study the quality and composition of $\mathrm{Sn}$-doped $\mathrm{ZnO}$ nanostructured samples [33]. EDX analysis confirmed the presence of $\mathrm{Zn}, \mathrm{O}$ and $\mathrm{Sn}$ elements in the synthesized materials. Fig. 4a shows the spectrum of pure $\mathrm{ZnO}$ with two to three high intense peaks which are associated with $\mathrm{Zn}$ and $\mathrm{O}$ atoms.

The measured atomic percentage of these elements is about 42.04 and 57.96, respectively. Fig. 4b and Fig. 4d exhibit the results of EDX analysis of Sn-doped $\mathrm{ZnO}$ nanoparticles; the measured $\mathrm{Sn}$ contents are 0.52, 3.27, 8.03 and 9.68 atomic percentage, respectively, for the four nominal compositions of $5 \mathrm{wt} . \%, 10 \mathrm{wt} . \%, 15 \mathrm{wt} . \%$ and $20 \mathrm{wt} . \%$, indicating that Sn percentage in the $\mathrm{ZnO}$ nanoparticles increases according the nominal loading of Sn [33, 34]. Results of elemental analysis of $\mathrm{ZnO}$ doped by different concentrations of $\mathrm{Zn}$ are compared in Table 3.

\section{Conclusions}

$\mathrm{Sn}$ doped $\mathrm{ZnO}$ nanoparticles have been synthesized using a simple chemical solution method. The average grain size of pure $\mathrm{ZnO}$ is $21 \mathrm{~nm}$ and it decreases up to $17 \mathrm{~nm}$ for the sample doped with $20 \mathrm{wt} . \% \mathrm{Sn}$. The increased Sn concentration results in the agglomeration which has taken place. XRD results show that the material is polycrystalline with preferred orientations $\left(\begin{array}{lll}1 & 0 & 1\end{array}\right)$ and $\left(\begin{array}{lll}0 & 1 & 5\end{array}\right)$. 
Table 3. Compositional analysis of synthesized Sn doped $\mathrm{ZnO}$ nanoparticles at 0 wt. \%, 5 wt. $\%, 10$ wt.\%, 15 wt. $\%$ and $20 \mathrm{wt} \%$.

\begin{tabular}{ccccccccccc}
\hline & \multicolumn{2}{c}{$\mathrm{ZnO}-0 \% \mathrm{Sn}$} & \multicolumn{2}{c}{$\mathrm{ZnO}-5 \% \mathrm{Sn}$} & \multicolumn{2}{c}{$\mathrm{ZnO}-10 \% \mathrm{Sn}$} & \multicolumn{2}{c}{$\mathrm{ZnO}-15 \% \mathrm{Sn}$} & \multicolumn{2}{c}{$\mathrm{ZnO}-20 \% \mathrm{Sn}$} \\
Element & {$[$ [wt.\%] } & [at.\%] & [wt.\%] & [at.\%] & [wt.\%] & [at.\%] & [wt.\%] & [at.\%] & [wt.\%] & [at.\%] \\
\hline \hline $\mathrm{Zn}$ & 74.77 & 42.04 & 75.09 & 43.86 & 82.89 & 65.63 & 57.70 & 37.93 & 39.34 & 22.21 \\
$\mathrm{O}$ & 25.23 & 57.96 & 23.31 & 55.62 & 9.61 & 31.10 & 20.12 & 54.04 & 29.53 & 68.12 \\
- & - & - & 1.61 & 0.52 & 7.49 & 3.27 & 22.18 & 8.03 & 31.13 & 9.68 \\
Total & 100 & 100 & 100 & 100 & 100 & 100 & 100 & 100 & 100 & 100 \\
\hline
\end{tabular}

It is observed that up to $10 \mathrm{wt} . \%$ Sn doping, the peak intensity corresponding to plane $\left(\begin{array}{lll}1 & 0 & 1\end{array}\right)$ increases and thus the grain size increases, while for Sn concentration above $10 \mathrm{wt} . \%$, the peak intensity decreases which indicates poor crystallinity of the samples. FESEM results show the fine granular structure for 0 and $5 \mathrm{wt} . \%$ Sn doping in $\mathrm{ZnO}$. The structure has been disturbed above the Sn doping level of $10 \mathrm{wt} . \%$ that might be due to the incorporation of excessive amount of Sn metal into the crystal structure of $\mathrm{ZnO}$ materials.

\section{References}

[1] Li G., Hu G.G., Zhou H.D., Fan X.J., Li X.G., Mater. Chem. Phys., 75 (2002), 101.

[2] Miura K., Masuda M., Itoh M., Horikawa T., MACHIDA K.I., J. Alloy. Compd., 408 (2006), 1391.

[3] Huang S., Wang L., LiU L., Hou Y., Li L., Agron. Sustain. Dev., 35 (2015), 369.

[4] Gonchar A., Gorelik S., Katynkina S., Letyuk L., Ryabov I., J. Magn. Magn. Mater, 215 (2000), 221.

[5] Huang J., Zhuang H., Li, W., Mater. Res. Bull., 38 (2003), 149.

[6] Pereira F.M.M., Santos M.R.P., Sohn R.S., Almeida J.S., Medeiros A.M.L., J. Mater. Sci.Mater. El., 20 (2009), 408.

[7] CHo H.S., KIM S.S., IEEE T. Magn., 35 (1999), 3151.

[8] Nedkov I., PetKov A., Karpov V., IEEE T. Magn., 26 (1990), 1483.

[9] Shen G., Xu M., Xu Z., Mater. Chem. Phys., 105 (2007), 268

[10] Sugimoto S., Haga K., Kagotani T., Inomata K., J. Magn. Magn. Mater, 290 (2005), 1188.

[11] Ali I., Islam M.U., Awan M.S., Ahmad M., J. Alloy. Compd., 547 (2013), 118.

[12] Batoo K.M., Kumar S., Lee C.G., Curr. Appl. Phys., 9 (2009), 826.

[13] Pires G.F.M., Rodrigues H.O., Almeida J.S., Sancho E.O., Goes J.C., Costa M.M., Denardin J.C., Sombra, A.S.B., J. Alloy. Compd., 493 (2010), 326.
[14] Fister M.J., De Geus A., Rhines W.C., Hu J., CASSIDY R., IEEE T. Nucl. Sci., 43 (1996), 2874.

[15] Koops C.G., Phys. Rev., 83 (1951), 121.

[16] Reddy M.B., Reddy P.V., J. Appl. Phys., 75 (1994), 6125.

[17] Watawe S.C., Sarwade B.D., Bellad S.S., SUTAR B.D., Chougule B.K., J. Magn. Magn. Mater., 214 (2000), 55.

[18] Tsakaloudi V., Kogias G., Zaspalis V.T., J. Alloy. Compd., 588 (2014), 222.

[19] Rezlescu N., Rezlescu E., Phys. Status Solidi A, 23 (1974), 575.

[20] PIllai P.K.C., Polymeric Electrets, Plastics Engineering, New York, 1995.

[21] Ounnunkad S., Winotai P., J. Magn. Magn. Mater., 301 (2006), 292.

[22] Bsoul I., Mahmood S.H., J. Alloy. Compd., 489 (2010), 110.

[23] Lechevallier L., Le J.M., Breton J.F., Harris I.R., J. Magn. Magn. Mater., 269 (2004), 192.

[24] LeE S.W., An S.Y., Shim I.B., Kim C.S., J. Magn. Magn. Mater., 290 (2005), 231.

[25] Iqbal M.J., AshiQ M.N., Gul I.H., J. Magn. Magn. Mater., 322 (2010), 1720.

[26] El Ata A.A., Reicha F.M., Ali M.M., J. Magn. Magn. Mater., 292 (2005), 17.

[27] Sawadh P.S., KulKarni D.K., B. Mater. Sci., 24 (2001), 47.

[28] Jia L., Luo J., Zhang H., Xue G., Jing Y., J. Alloy. Compd., 489 (2010), 162.

[29] Kumar M.P, Shankarappa T., Kumar B.V., NAGARAJA N., Solid State Sci., 11 (2009), 214.

[30] IQbal M.J., AshiQ M.N., Chem. Eng. J., 136 (2008), 383.

[31] Bahsi Z.B., Oral A.Y., Opt. Mater., 29 (2007), 672.

[32] Mott N.F., DAVIs E.A., Electronic Processes in NonCrystalline Materials, Clarendon Press, London, 1979.

[33] PRAKash T., Jayaprakash R., Espro C., Neri G.,Kumar E.R.,, J. Mater. Sci., 49 (2014), 1776.

[34] Sirdeshmukh L., Kumar K.K., LaXman S.B., Krishna A.R., Sathaiah G., B. Mater. Sci., 21 (1998), 219.

Received 2015-12-27 Accepted 2016-09-24 